\title{
AULAS DE CÁLCULO DIFERENCIAL E INTEGRAL ORGANIZADAS A PARTIR DE EPISÓDIOS DE RESOLUÇÃO DE TAREFAS: UM CONVITE À INSUBORDINAÇÃO CRIATIVA
}

\section{DIFFERENTIAL AND INTEGRAL CALCULUS CLASSES ORGANIZED UNDER SHIFT PROBLEM LESSONS: AN INVITATION TO THE CREATIVE INSUBORDINATION}

\author{
Alan Franco do Couto \\ Universidade Tecnológica Federal do Paraná - UTFPR Campus Londrina / alanfcouto@gmail.com
}

Maycon Odailson dos Santos da Fonseca

Secretaria Estadual de Educação - SEED/PR / santos califa@hotmail.com

André Luis Trevisan

Universidade Tecnológica Federal do Paraná - UTFPR Campus Londrina/PPGMAT /

andreluistrevisan@gmail.com

\section{Resumo}

Inspirados no conceito de insubordinação criativa, neste artigo apresentamos uma caracterização do nosso trabalho em ambientes de aprendizagem organizados por meio de episódios de resolução de tarefas. Relatamos, a partir de uma análise quantitativa e brevemente qualitativa dos resultados obtidos das resoluções apresentadas por estudantes ingressantes em turmas de cursos de engenharia de uma universidade federal, a "história" de evolução de uma das tarefas que compõem nosso ambiente. Na análise desse processo de refinamento da tarefa, com base nas reflexões dos pesquisadores, identificamos que a proposta de formulação de tarefas do tipo aberto-controlada mostrou-se mais promissora, considerando as condições reais de nosso ambiente de trabalho.

Palavras-chave: Ensino de Cálculo Diferencial e Integral. Episódios de Resolução de Tarefas. Recursos Tecnológicos. Ambiente de Aprendizagem. Insubordinação Criativa.

\section{Abstract}

Inspired by the concept of creative insubordination, in this paper we present a characterization of our work in learning environments organized through shift problem lessons. We report, in a quantitative and slightly qualitative analysis of the results obtained from the resolutions presented by incoming students in classes of engineering courses of a federal university, the "improvements history" of one task that comprehends our environment. In the analysis of this refinement process of the task, based on the researchers' thinkings, we identified that the open-controlled task formulation was more promising, considering the real conditions of our working environment.

Keywords: Differential and Integral Calculus Teaching. Shift Problem Lessons. Technological Resources. Learning Environment. Creative Insubordination. 


\section{Introdução}

A organização de ambientes de aprendizagem diferenciados como alternativa ao ensino diretivo ainda é um tabu, apesar das recomendações curriculares e das discussões no âmbito das pesquisas em Educação Matemática que vêm ocorrendo nas últimas décadas. Tradicionalmente, as disciplinas matemáticas, tanto na Educação Básica quanto (e principalmente) no Ensino Superior, são "cartesianas", sustentadas pelo tripé definiçãoexemplo-exercício, seguido de uma avaliação acumulativa que prioriza a reprodução de procedimentos. Um dos efeitos gerados por essa tradição é tornar essas disciplinas, na visão dos estudantes, maçantes e algorítmicas, sem objetivos e desmotivadoras, principalmente para cursos de engenharia.

Temo-nos então debruçado em pensar a organização de ambientes de aprendizagem que, por um lado, difiram de aulas totalmente expositivas e oportunizem ao estudante assumir um papel mais ativo em seu processo de aprendizagem e, por outro, atendam demandas rotineiras da sala de aula e estejam alinhados com a organização didático-pedagógica proposta pela instituição, visando o comprometimento com currículo obrigatório, com o projeto político-pedagógico do curso e com a atribuição de uma nota ao fim do período. Para tal, buscamos respaldos em tendências metodológicas e resultados de pesquisas em Educação Matemática, que se mostram factíveis considerando nossas condições de trabalho (RAMOS; FONSECA; TREVISAN, 2016). Em especial, nosso foco tem sido a investigação de ambientes de ensino e aprendizagem de Cálculo Diferencial e Integral (CDI) em condições reais de ensino.

Tomando como pressuposto a importância de o estudante assumir um papel ativo em seu processo de aprendizagem, nossas aulas nas disciplinas de CDI I têm sido organizadas a partir da concepção de episódios de resolução de tarefas (PALHA, DEKKER; GRAVEMEIJER, 2015) ${ }^{1}$. Essa dinâmica de aula foge, em aspectos metodológicos, a uma aula "usual" de CDI e vai ao encontro dos ideais da insubordinação criativa, descritos por D'Ambrosio e Lopes (2015).

Gutiérrez (2013 apud D’AMBROSIO; LOPES, 2015, p. 3-4) destaca que, no ensino da Matemática, insubordinações criativas de professores manifestam-se por atos como: "questionar as formas como a Matemática é apresentada na escola; enfatizar a humanidade e a incerteza da disciplina de Matemática; posicionar os alunos como autores da Matemática e desafiar os discursos discriminatórios sobre os alunos". Reconhecemo-nos assim como insubordinados criativos a partir do momento em que, na ação docente, atrevemo-nos a criar e a ousar, pois desejamos que os estudantes façam a matemática ganhar sentido, investiguem as situações-problema criativamente, estimulando-os a se envolverem na resolução de tarefas e não apenas a realizarem cálculos, trabalhando sempre que possível em grupos. Nesse sentido,

[...] é preciso questionar os posicionamentos metodológicos rígidos comumente encontrados nas escolas e universidades, pois o ensino é organizado em disciplinas e a atuação do professor é subordinada a cumprir determinadas diretrizes. Deve-se reconhecer que a educação tem uma

\footnotetext{
1 Episódios de resolução de tarefas é uma adaptação do termo shift problem lessons desses autores e que vem sendo utilizada em nossos relatórios de pesquisa.
} 
dinâmica própria, ditada pelas condições reais da escola, dos alunos e dos professores [...] (informação verbal). ${ }^{2}$

Uma sala de aula é um ambiente de heterogeneidade de mentes, condições sociais e políticas, habilidades específicas e outros diversos aspectos inerentes ao ser humano. Diante disso, concordamos que

O professor necessita tomar decisões rapidamente em suas ações pedagógicas. Da mesma forma, o pesquisador que desenvolve estudos em Educação também precisa considerar essa complexidade educativa e tomar decisões sobre como investigar os diversos contextos (D'AMBRÓSIO; LOPES, 2015).

Para atender esses ideais, adotamos como metodologia a pesquisa de desenvolvimento (tradução proposta por Barbosa e Oliveira (2014) para design research), por meio do desenho de tarefas para aulas de CDI, com a realização de ciclos de investigação nos quais o material é constantemente aprimorado a partir de dados coletados em contextos reais de ensino - nossa realidade escolar. Trata-se de uma busca de respostas aos desafios que, enquanto educadores, nos são apresentadas nas múltiplas situações decorrentes da atividade profissional diária, para os quais não encontramos respostas pré-estabelecidas (D'AMBRÓSIO; LOPES, 2015).

O objetivo deste trabalho é discutir a formulação de uma tarefa, que intenta atribuir um design experimental à atividade matemática (BORBA; SILVA; GADANIDIS, 2015), por meio da integração de um recurso computacional (no caso, um aplicativo disponibilizado no GeoGebra Materials ${ }^{3}$ ), num relato que reflete a importância de se insubordinar frente às perspectivas usuais de ensino de CDI, levando-se sempre em consideração a possibilidade de readequação pedagógica.

\section{Episódios de resolução de tarefas: uma reinvenção da aula tradicional}

O trabalho com episódios de resolução de tarefas mostra-se como uma proposta exequível, que busca minimizar a lacuna entre o "desejado" e o "possível", uma vez que as condições reais de ensino em nossas turmas de CDI inviabilizam a realização de um trabalho que atenda plenamente, ao longo de todo o curso, pressupostos de tendências para o ensino de Matemática apontadas pelas pesquisas em Educação Matemática, como a resolução de problemas, a investigação e a modelagem matemática.

Tais episódios constituem-se como momentos do curso nos quais os estudantes são convidados a explorar intuitivamente, a partir da resolução de tarefas, conceitos que auxiliem na elaboração de conjecturas sobre a situação-problema, testando-as e compartilhando-as com seus colegas. No contexto do CDI I (disciplina contemplada em 90 horas-aula no $1^{\circ}$ semestre dos cursos de Engenharia da instituição na qual estamos

\footnotetext{
2 Recortes da palestra do professor Dr. Ubiratan D'Ambrosio, durante a abertura da $1^{\text {a }}$ Conferência Internacional de Insubordinação Criativa em Educação Matemática, ocorrida em 1ํ de agosto, 2017, São Paulo - SP.

${ }^{3}$ https://www.geogebra.org/materials.
} 
vinculados ${ }^{4}$ ), temos dedicado cerca de 25 horas do curso (cerca de 10 encontros de 3 horas-aula de 50 minutos) a esses episódios, planejados para anteceder o estudo "formal" dos conceitos de função de uma variável real, limite, derivada e integral.

Nesses episódios, os estudantes inicialmente trabalham em grupos e o professor os questiona durante a resolução de tarefas (criadas e/ou adaptadas de livros didáticos/materiais curriculares) que envolvam conteúdos que não foram "apresentados" na lousa, mas que podem ser explorados intuitivamente por meio dessa dinâmica. Tomando por base as ideias apresentadas por Watson et al. (2013), por tarefa estamos entendendo "o amplo espectro composto por 'coisas a fazer' pelos estudantes em sala de aula, o que inclui desde a execução de exercícios algorítmicos até a realização de investigações ou construção de modelos matemáticos" (TREVISAN; BORSSOI; ELIAS, 2015, p.3).

Uma das formas de insubordinação que buscamos aplicar em nosso meio de ensino é a utilização de recursos tecnológicos. No desenho das tarefas, procuramos agregar as potencialidades computacionais numa tentativa de tornar a disciplina mais "palpável" e possibilitar aos estudantes a experimentação por meio de aspectos gráficos e dinâmicos (BORBA; SILVA; GADANIDIS, 2015). Para isso, lançamos mão de objetos de aprendizagem, simuladores, gráficos interativos, vídeos, dentre outros, como recursos a serem agregados no trabalho com episódios de resolução de tarefas. Gifs ${ }^{5}$ são outros recursos inseridos nas tarefas para conceituação gráfica de alguns temas.

Na Figura 1, por exemplo, mostramos um gráfico interativo presente em uma tarefa sobre integrais definidas. Aqui, o estudante pode inserir funções quaisquer e intuir graficamente propriedades que estão postuladas textualmente. Uma possibilidade de investigação visual dessas seria praticamente impossível apenas com o livro didático comum. Recursos como esses são coletados do GeoGebra Materials, a plataforma online do conhecido software matemático de código aberto, GeoGebra, encontrados na internet ou construídos pelo próprio professor e estudantes de iniciação científica, especialização e mestrado. Destacamos, também, a organização de um site ${ }^{6}$ que, além de agregar tais recursos, apresenta como elemento diferencial da nossa forma de trabalho uma quebra do paradigma da linearidade de apresentação de conteúdo (limite, derivada e integral), que passa a receber um tratamento em espiral (TREVISAN; MENDES, 2017), mantendo alguma similaridade na forma com que os conceitos foram formalizados ao longo da história do CDI, como destacado por Vallejo e Pluvinage (2009).

A subversão responsável se faz presente em nossos atos a partir do momento em que questionamos a forma usual de apresentação dos conteúdos do CDI, realçando sua incerteza numa tentativa de torna-la uma disciplina mais humana e menos robótica, ao encontro do que aponta Gutiérrez (2013 apud D’AMBROSIO; LOPES, 2015).

\footnotetext{
${ }^{4} \mathrm{O}$ primeiro autor enquanto graduando em Engenharia de Materiais e estudante de iniciação científica, o segundo enquanto mestre em Ensino de Matemática e o terceiro enquanto docente e orientador do trabalho, todos pela UTFPR - campus Londrina.

${ }^{5}$ Gifs são imagens constituídas por várias outras imagens que, no fim, formam uma animação.

${ }^{6}$ www.calculointerativo.com.br. Para maiores detalhes sobre a construção do site, consultar o trabalho de Couto e Trevisan (2017).
} 


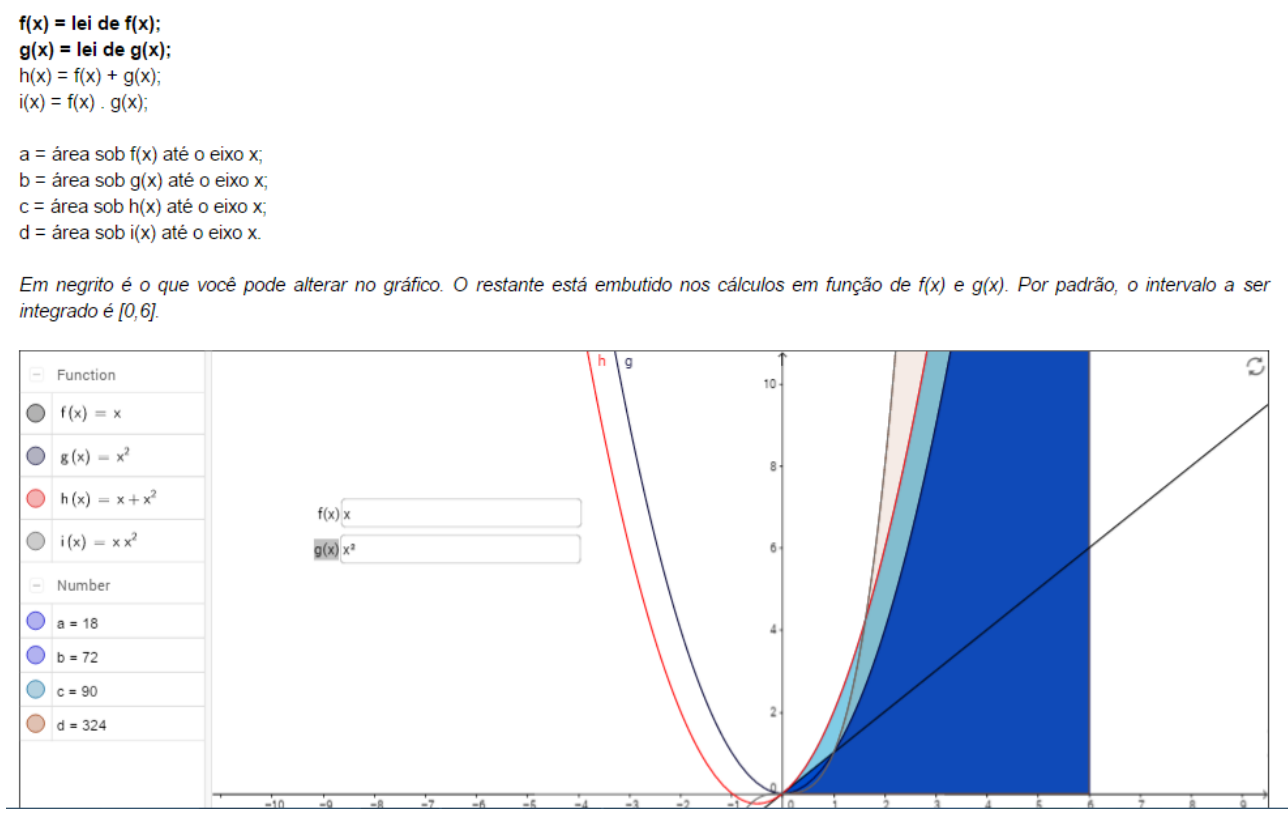

Figura 1 - Gráfico interativo que pode auxiliar a intuir visualmente propriedades de integrais. Fonte: os autores.

Segundo Jean Dieudonné, como publicado em Reis (2009), a intuição é um aspecto importante desde antes da "invenção" do CDI, enquanto que definições, conceitos e teoremas como hoje são lecionados resultam de um processo de formalização que se deu ao longo de muitos anos. Dessa forma, necessita-se dosar o rigor matemático e a intuição. Não havendo esta preocupação, formam-se pessoas com dificuldades em abordar problemas de maneira criativa. Visto que nosso público-alvo se constitui de futuros engenheiros ${ }^{7}$, que buscarão soluções para problemas, é necessário estimulá-los, durante a resolução de tarefas, a pensar criativamente e, principalmente, trabalhar em grupo. Em geral, desenhamos previamente tarefas que possibilitem aos estudantes explorar intuitivamente conceitos que serão posteriormente sistematizados. Os grupos são formados logo no início da aula e os estudantes têm um tempo pré-determinado pelo professor para discutir e tentar resolver a tarefa. Iniciado o episódio, o professor passa a orientar os estudantes sobre possíveis caminhos ou ouvi-los e provocá-los a investigar mais sobre suas próprias conjecturas.

Lithner (2008) descreve que a dificuldade em lidar com problemas mais complexos em Matemática é comum porque a maior parte dos estudantes é condicionada a resolvêlos baseando-se em exercícios resolvidos ou alguma anotação semelhante, ocorrendo um desestímulo ao raciocínio criativo. Apesar das demandas rotineiras do contexto real de ensino (turmas numerosas, currículo a se cumprir, atribuição de nota etc.), os estudantes não devem ser treinados apenas a resolver contas avulsamente, com excessiva memorização de conceitos e técnicas, mas a raciocinar diante de uma situação, proposta a partir de tarefas que se constituam como um problema a ser resolvido. Por isso, faz-se necessário insubordinarmo-nos criativamente, buscando alternativas metodológicas que se

\footnotetext{
${ }^{7}$ Engenhar: traçar, idear, inventar. Disponível em: <https://www.dicio.com.br/engenhar>. Acessado em: 13 ago. 2017.
} 
julguem adequadas às condições escolares de nossos estudantes, ajustando a prática docente e o "ser humano" frente às suas limitações naturais (Figura 2).

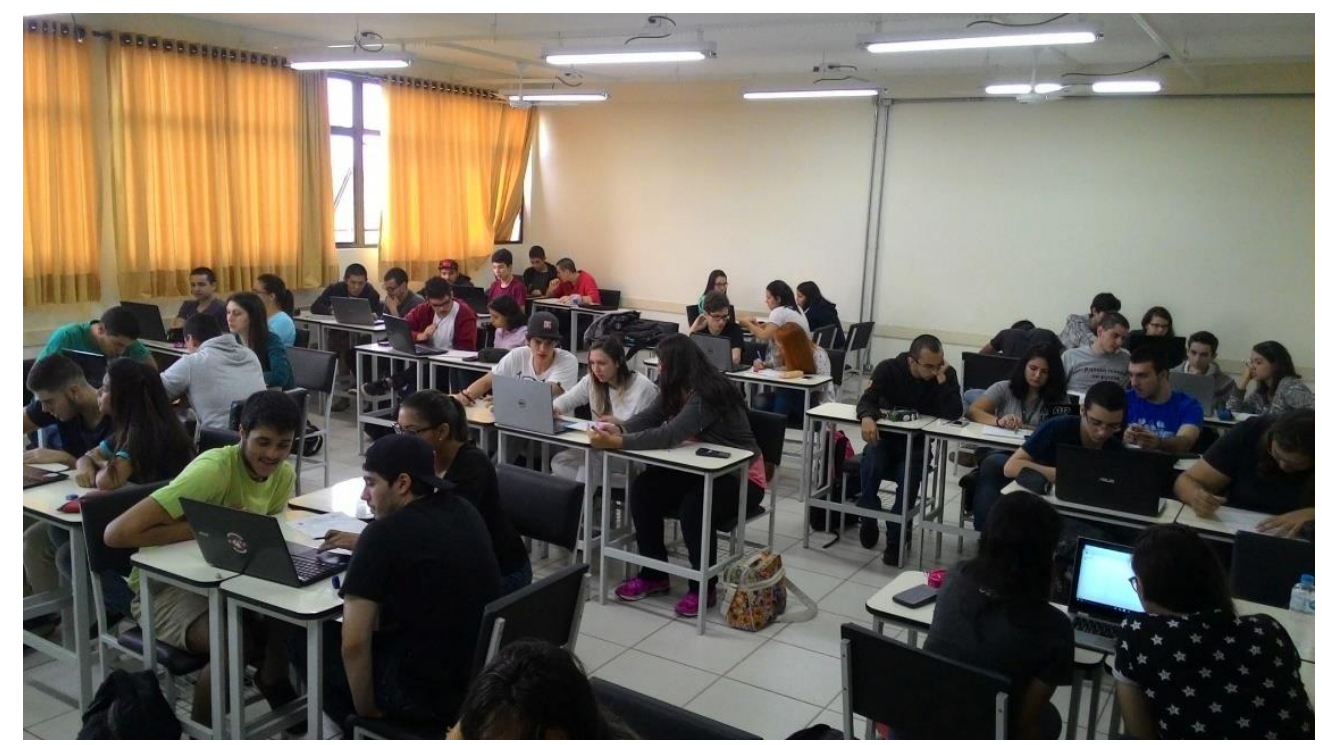

Figura 2 - Um episódio de resolução de tarefas durante uma aula de CDI. Fonte: os autores.

\section{A pesquisa de desenvolvimento: um caminho para investigar o "desenho" de tarefas}

Esse trabalho tem breve natureza qualitativa, de cunho interpretativo, caracterizado como uma pesquisa de desenvolvimento (BARBOSA; OLIVEIRA, 2015). A expressão aqui usada é uma adaptação para a língua portuguesa de design research. De modo geral, "refere-se àquelas investigações que envolvem delineamento, desenvolvimento e avaliação de artefatos para serem utilizados na abordagem de determinado problema, à medida que se busca compreender/explicar suas características, usos e/ou representações" (BARBOSA; OLIVEIRA, 2015, p. 527).

O desenho de tarefas, enquanto "processo de elaboração, criação e preparação de situações matemáticas a serem aplicadas em sala de aula" (MOREIRA; GUSMÃO; MOLL, 2016, p.789) configura-se como importante, porém complexa, atividade no escopo dessa proposta e tem sido foco de nossas investigações. Trata-se de uma "construção que não ocorre de forma rápida e aligeirada, que demanda tempo e estudo" (ibid.). Assim como ocorreu no projeto conduzido por Barbosa e Oliveira (2016, p. 528), é nossa intenção de pesquisa realizar o "delineamento e desenvolvimento de materiais para subsidiar professores que ensinam Matemática interessados em adotar propostas de mudanças pedagógicas, bem como investigar processos de produção e uso desses materiais".

A tarefa cuja análise é apresentada na sequência foi proposta para estudantes recém-ingressos em turmas de cursos de engenharia do campus Londrina da UTFPR, na disciplina de CDI I, na qual o terceiro autor atua como docente, durante a segunda semana de aulas do primeiro e segundo semestres do ano de 2016. Após a resolução, as tarefas foram recolhidas para análise qualitativa e quantitativa por parte dos pesquisadores, de acordo com critérios pré-estabelecidos por estes. 


\section{Discussão e análise de dados}

Apresentamos, a seguir, uma análise da "história" de evolução de uma das tarefas que compõem nosso ambiente de aprendizagem pautado em episódios de resolução de tarefas, buscando evidenciar, de forma articulada com pressupostos da insubordinação criativa, seu processo de refinamento, com base nas reflexões dos pesquisadores.

\section{Uma (primeira) proposta (literalmente) aberta ${ }^{8}$}

O desenho de tarefas como um papel do docente, por si só, caracteriza uma insubordinação ao sistema de ensino atualmente predominante, uma vez que procura oporse às práticas usuais que priorizam "uma abordagem apenas técnica, com uma perspectiva que restringe a Matemática a si mesma, [...] adestrar a pessoa em habilidades de cálculo e no uso de algoritmos, negando-lhe o conhecimento matemático necessário para a leitura de mundo a que ela tem direito (D'AMBROSIO; LOPES, 2015, p. 12)".

E se desenhássemos uma tarefa verdadeiramente aberta, onde os estudantes pudessem investigar uma situação sem exatamente nenhuma dica ou ponto de partida, apenas com o conhecimento elaborado nas aulas anteriores, como seria? Utilizando essa indagação como força motriz, na segunda semana de aulas do primeiro semestre de 2016, propusemos aos estudantes a seguinte tarefa: Investigue $o$ aplicativo e anote o que julgar pertinente. $\mathrm{O}$ aplicativo em questão tratava-se de um gráfico interativo, mostrado na Figura 3.

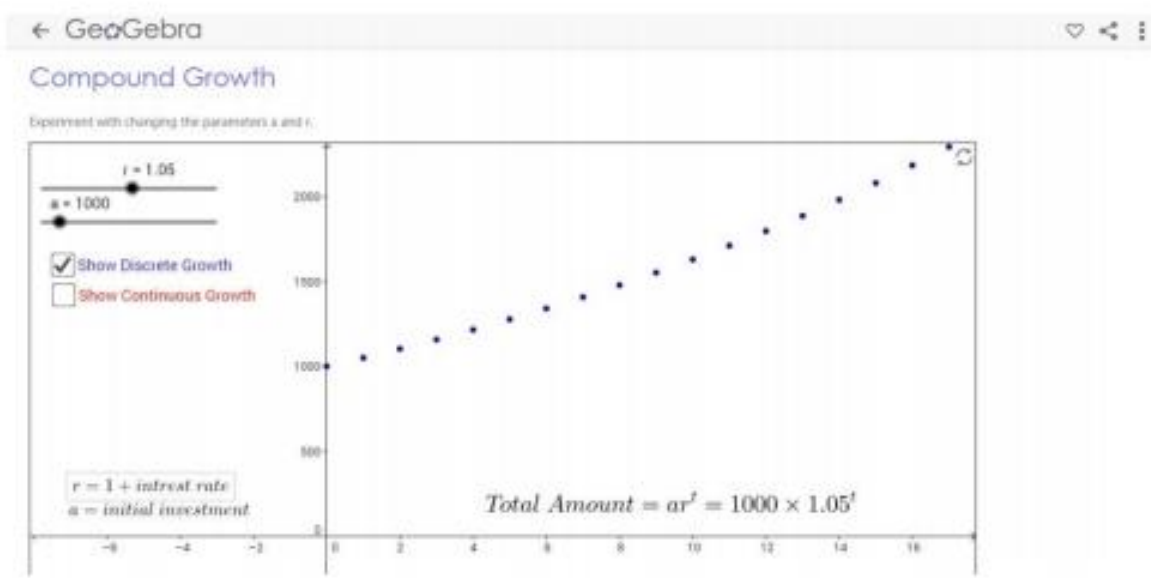

Figura 3 - Gráfico interativo utilizado na proposta de tarefa aberta. Fonte: Couto, Trevisan e Fonseca (2016a).

A ideia era observar, por meio da análise da produção escrita entregue pelos estudantes, se estes foram capazes de identificar elementos do gráfico da função exponencial não "formalizados" em sala de aula até aquele momento, ao manipularem parâmetros da equação. Inicialmente, os autores elencaram quatro aspectos que poderiam ser observados por meio de algumas "brincadeiras" com tais parâmetros:

i) A interferência dos valores de $a$ e de $r$ no comportamento da curva;

${ }^{8}$ Recorte da pesquisa de Couto, Trevisan e Fonseca (2016a). 
ii) O crescimento/decrescimento da curva;

iii) A taxa de variação da curva;

iv) A concavidade da curva.

Ainda que não utilizassem terminologia específica (como taxa de variação), os estudantes poderiam observar esses aspectos (a curva cresce mais ou menos rápido), já que haviam trabalhado com o Excel e o GeoGebra em aulas anteriores, observando o comportamento de funções de domínio discreto (progressões aritméticas e geométricas), similarmente ao mecanismo de funcionamento do aplicativo em questão (Figura 3).

O primeiro momento da tarefa foi sua proposição para resolução extraclasse. Num segundo momento, essas tarefas foram recolhidas e analisadas pelos pesquisadores, separando as produções dos estudantes em grupos segundo o número de aspectos que conseguiram identificar. A separação foi feita como G1 até G5, sendo que G1 era um grupo formado por estudantes que conseguiram, informalmente, abranger todos os quatro aspectos, enquanto que G5 era um grupo formado por estudantes que não conseguiram identificar nenhum dos aspectos. As tarefas foram, então, devolvidas aos estudantes com questionamentos provocativos, numa tentativa de fazê-los irem além do que já haviam investigado, exceto aos estudantes do grupo G1, que já haviam atingido o esperado.

$O$ terceiro momento se deu quando a tarefa foi novamente entregue pelos estudantes. Após uma segunda análise, percebemos que boa parte deles se engajaram mais na abordagem exploratória, o que fortemente sugere que a insubordinação ao sistema de ensino convencional $e$ dar aos estudantes uma oportunidade de repensarem matematicamente, sem desmotivá-los com uma "nota", parece ser didaticamente razoável no contexto de resoluções de tarefas abertas. Além disso, compreendemos que a interpretação muitas vezes não é tão trivial como se pensa ao elaborar uma tarefa, indicando que essa nova oportunidade é agir responsavelmente como educadores e querer que 0 estudante entenda o que está fazendo. Este fato nos fez pensar que, muito provavelmente, houve um problema de compreensão sobre o que era para ser feito nessa tarefa e essa confusão foi, em partes, amenizada quando tais estudantes tiveram ao menos um caminho inicial ou ideia para se nortear.

Acreditamos que guiar em partes o estudante não deixa facilitada a resolução de uma situação-problema, mas pode instigá-lo a ir mais a fundo em sua investigação matemática. Então, por que não trazer essa ideia logo de início? A partir desse princípio é que se deu o segundo episódio dessa tarefa, ou seja, a sua "evolução".

\section{Um novo desenho: a proposta "aberto-controlada"}

A insubordinação criativa nos possibilita sempre inovar e a "desobedecer com responsabilidade" aos parâmetros usuais, conforme julga-se necessário. Por isso, percebendo que a proposta demasiadamente aberta se tornou mais um instrumento de detecção de dificuldades de raciocínio e interpretação dos estudantes do que propriamente uma oportunidade de fazer matemática, redesenhamos a tarefa, adequando-nos à realidade anteriormente observada. Coube-nos a seguinte reflexão: "o que queremos, como docentes e pesquisadores em Educação Matemática, que nossos estudantes entendam 
com essa tarefa?". Pode parecer trivial, mas, didaticamente, é de suma importância a clareza de um enunciado de proposição. Reflexões como esta fazem parte do que foi mencionado a respeito de mudanças que se fazem necessárias, hora ou outra, dentro do contexto do ensino e aprendizagem.

A reformulação dessa tarefa e seus resultados advêm do trabalho de Couto, Trevisan e Fonseca (2016b). Nele, foram aplicadas questões do tipo "aberto-controladas" (BORBA; SILVA; GADANIDIS, 2015), ou seja, que serviriam de ponto de partida para os estudantes raciocinarem sobre a situação, mas sem direcioná-los pontualmente a uma solução. Retomando os aspectos que poderiam ser explorados no gráfico da função exponencial (Figura 3), elaboramos as seguintes questões $\left(Q_{i}\right)$ :

i) O que este gráfico possivelmente representa? $\left(Q_{1}\right)$

ii) Há dois parâmetros na expressão. Explore e discorra sobre o papel de cada um deles no comportamento da curva. $\left(Q_{2}\right)$

iii) Em termos de crescimento, como os valores da função variam? Essas variações dependem dos parâmetros? (Q3)

iv) Para qualquer valor de $r$ a função é côncava para cima (exceto para $r=1$ ). Este fato implica que ela é sempre crescente? (Q4)

Após o recolhimento das tarefas resolvidas (também propostas para serem resolvidas em horário extraclasse), fizemos as análises estabelecendo uma "nota" de 0 a 2, onde 2 era atribuído a boas investigações e 0 a investigações pouco detalhadas e/ou com observações equivocadas. O Quadro 1 foi construído a partir dos dados coletados e dos critérios pré-estabelecidos pelos pesquisadores.

Quadro 1 - Análise de dados em questão do tipo aberto-controlada. Fonte: Couto, Trevisan e Fonseca (2016b).

\begin{tabular}{|c|c|c|c|c|}
\hline \multirow{3}{*}{ Total } & \multicolumn{3}{|c|}{ Número de alunos } & Questionamento \\
\cline { 2 - 5 } & 28 & 11 & 20 & Q1 \\
\cline { 2 - 5 } & 8 & 28 & 23 & Q2 \\
\cline { 2 - 5 } & 17 & 23 & 19 & Q3 \\
\cline { 2 - 5 } & 16 & 24 & 19 & Q4 \\
\hline Nota & 0 & 1 & 2 & - \\
\hline
\end{tabular}

Pela quantidade de estudantes com critério "0" para $Q_{1}$, pode ser que ela tenha ficado aberta a muitas possibilidades que essa função poderia representar, deixando-os inseguros a respeito de uma resposta genérica. Uma proposta factível para resolver este problema, como indicado no trabalho, seria fazer outra reformulação nessa questão. A maioria dos que conseguiram atingir nota 2 nessa questão e indicaram algum fenômeno que pudesse ser modelado pela expressão anotaram aplicação financeira, muito provavelmente induzidos a esse pensamento justamente porque, na interface do aplicativo, existem termos característicos do setor financeiro.

Para as outras questões, fotos de algumas resoluções foram colocadas para exemplificar, uma classificada em cada critério, discorrendo sobre as diversas respostas 
coletadas. Aqui, essas fotos e comentários não serão discutidos novamente porque focamos em demonstrar, pelos resultados quantitativos e brevemente qualitativos, que a metodologia de proposição de uma tarefa aparenta ter muita influência na forma com que os estudantes trabalham o problema. Sendo assim, pelo intuito do trabalho e pelo Quadro 1, observa-se que a maior dificuldade dos estudantes se concentrou justamente na questão que ainda se mostrou "aberta demais".

\section{Considerações finais}

O ambiente de aprendizagem de CDI pode ser mais dinâmico quando o professor decide mudar suas condutas e passa a ser um insubordinado criativo frente às linearidades usualmente presentes nesse âmbito. As tarefas propostas em nosso ambiente têm se mostrado um recurso interessante para a disciplina, pois são elaboradas considerando elementos essenciais para a exploração e discussão de conceitos centrais da disciplina, de forma intuitiva.

Nesse contexto, os estudantes são convidados a trabalhar a partir de tarefas investigativas, numa tentativa de posicioná-los como autores da Matemática, buscando perceber e respeitar seu processo de desenvolvimento intelectual e emocional (D'AMBROSIO; LOPES, 2015). A organização de ambientes de aprendizagem pautados em episódios de resolução de tarefas tem buscado, por um lado, incorporar às nossas ações educacionais contribuições de pesquisas em Educação Matemática (como a Resolução de Problemas, a Modelagem Matemática e as Investigações Matemáticas), e por outro "adequar-se" à nossa realidade educacional.

Como resultado das investigações aqui apresentadas, identificamos que tarefas no formato aberto-controlado têm se adequado ao nosso processo de ensino, ao menos nos episódios iniciais da disciplina de CDI. Por um lado, esse formato de tarefa possibilita aos estudantes a realização de experimentações com tecnologias, oferecendo-os meios para criar e conectar diferentes (e múltiplos) tipos de representações de objetos matemáticos, gerando conjecturas matemáticas (BORBA; SILVA; GADANIDIS, 2015). Por outro lado, mantém um desenho ao qual os estudantes estão habituados: como se fossem "comandados" pelo professor.

Frente aos resultados relatados, concluímos que uma boa maneira de verificar as inúmeras possibilidades, quando se trata de ensino e aprendizagem, é testando novas ideias sempre, sendo insubordinados até mesmo às nossas próprias conjecturas anteriores.

\section{Agradecimentos}

Agradecemos ao CNPq pelo financiamento por meio do Edital Universal 14/2014 (Processo 457765/2014-3).

\section{Referências}

BARBOSA, J. C.; OLIVEIRA, A. M. P. Por que a pesquisa de desenvolvimento na Educação Matemática? Perspectivas da Educação Matemática, v. 8, p. 526-546, 2015. 
BORBA, M. C.; SILVA, R. S. R.; GADANIDIS, G. Fases das tecnologias digitais em Educação Matemática: sala de aula e internet em movimento. 1 ed. 1 reimp. Belo Horizonte: Autêntica Editora, 2015. p. 45-73.

COUTO, A. F.; TREVISAN, A. L.; FONSECA, M. O. S. Análise de uma tarefa envolvendo o uso de um aplicativo do GeoGebra Tube no ensino de função exponencial. In: Congresso Brasileiro do Geogebra, 1., 2016a, Natal. Anais... Rio Grande do Norte: Edufersa, 2016a. p. 55-59.

COUTO, A. F.; TREVISAN, A. L.; FONSECA, M. O. S. Análise de uma tarefa investigativa proposta a estudantes de Cálculo por meio de questões do tipo 'aberto-controladas'. In: Simpósio Nacional de Ensino e Aprendizagem, SEA, 3., 2016b, Londrina. Anais... Londrina: Editora da UTFPR, 2016b. p. 1-9.

COUTO; A. F.; TREVISAN, A.L. Cálculo Interativo: um ambiente de suporte às aulas de Cálculo Diferencial e Integral. Hipátia: Revista Brasileira de História, Educação e Matemática, 2017. No prelo.

D'AMBROSIO, B. S.; LOPES, C. E. Insubordinação Criativa: um convite à reinvenção do educador matemático. Bolema, v. 29, n. 51, p.1-17, 2015.

LITHNER, J. A research framework for creative and imitative reasoning. Educational Studies in Mathematics, v. 67, n. 3, p. 255-276, 2008.

MOREIRA, C. B.; GUSMÃO, Tania C. R. S.; MOLL, Vicenç Font. O que Tem Dentro? O que Mudou? Desenho de Tarefas para Promover Percepções Matemáticas na Educação Infantil. Perpectivas da Educação Matemática, v. 9, p. 796-807, 2016.

PALHA, S.; DEKKER, R.: GRAVEMEIJER, K. The effect of shift-problem lessons in the mathematics classroom. Internacional Journal of Science and Mathematics Education. Ministry of Science and Technology, Taiwan, v. 13, p. 1589-1623, 2015.

RAMOS, N. S.; FONSECA, M. O. S.; TREVISAN, A. L. Ambiente de aprendizagem de Cálculo Diferencial e Integral pautados em episódios de resolução de tarefas. In: Simpósio Nacional de Ensino de Ciência e Tecnologia, SINECT, 5., 2016, Ponta Grossa. Anais... Ponta Grossa: Editora da UTFPR, 2016. p. 1-11.

REIS, F. S. Rigor e intuição no ensino de cálculo e análise. In: FROTA, Maria Clara Rezende e NASSER, Lilian. Educação Matemática no Ensino Superior: pesquisa e debates. Recife: SBEM, 2009. p. 81-97.

TREVISAN, A. L.; BORSSOI, A. H.; ELIAS, H. R. Delineamento de uma Sequência de Tarefas para um Ambiente Educacional de Cálculo. Seminário Internacional de Pesquisa em Educação Matemática, SIPEM, 6., 2015, Pirinópolis/GO. Anais... Brasília: SBEM, 2015. p. 1-12.

TREVISAN, A.L.; MENDES, M. T. Integral antes de derivada? Derivada antes de integral? E limite, no final? Uma proposta para organizar um curso de Cálculo. Educação Matemática Pesquisa, 2017. No prelo.

VALLEJO, C. A. C.; PLUVINAGE, F. Cálculo y Tecnología. El cálculo y su enseñanza, Cinvestav del Instituto Politécnico Nacional - México, p.1-15, 2009. 
WATSON, A; OHTANI, M; AINLEY, J.; FRANT, J. B.; DOORMAN, M.; KIERAN, C.; LEUNG, A.; MARGOLINAS, C.; SULLIVAN, P.; THOMPSON, D.; YANG, Y. Task Design in Mathematics Education. MARGOLINAS, $C$ et al. (Eds.). Proceedings... ICMI, 22. Oxford: ICMI, 2013, p. 9 -16.

Submissão: 15/08/2017

Aceite: 25/11/2017 